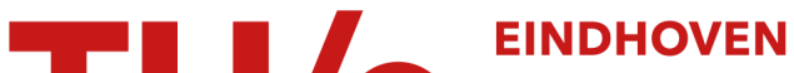 \\ UNIVERSITY OF \\ TECHNOLOGY
}

\section{Kinetic aspects of the emulsion polymerization of butadiene}

Citation for published version (APA):

Weerts, P. A., German, A. L., \& Gilbert, R. G. (1991). Kinetic aspects of the emulsion polymerization of butadiene. Macromolecules, 24(7), 1622-1628. https://doi.org/10.1021/ma00007a027

DOI:

10.1021/ma00007a027

Document status and date:

Published: 01/01/1991

\section{Document Version:}

Publisher's PDF, also known as Version of Record (includes final page, issue and volume numbers)

\section{Please check the document version of this publication:}

- A submitted manuscript is the version of the article upon submission and before peer-review. There can be important differences between the submitted version and the official published version of record. People interested in the research are advised to contact the author for the final version of the publication, or visit the $\mathrm{DOI}$ to the publisher's website.

- The final author version and the galley proof are versions of the publication after peer review.

- The final published version features the final layout of the paper including the volume, issue and page numbers.

Link to publication

\section{General rights}

Copyright and moral rights for the publications made accessible in the public portal are retained by the authors and/or other copyright owners and it is a condition of accessing publications that users recognise and abide by the legal requirements associated with these rights.

- Users may download and print one copy of any publication from the public portal for the purpose of private study or research.

- You may not further distribute the material or use it for any profit-making activity or commercial gain

- You may freely distribute the URL identifying the publication in the public portal.

If the publication is distributed under the terms of Article 25fa of the Dutch Copyright Act, indicated by the "Taverne" license above, please follow below link for the End User Agreement:

www.tue.nl/taverne

Take down policy

If you believe that this document breaches copyright please contact us at:

openaccess@tue.nl

providing details and we will investigate your claim. 


\title{
Kinetic Aspects of the Emulsion Polymerization of Butadiene
}

\author{
Pierre A. Weerts and Anton L. German* \\ Department of Polymer Chemistry, Eindhoven University of Technology, P.O. Box 513, \\ 5600 MB Eindhoven, The Netherlands
}

\author{
Robert G. Gilbert
}

Department of Theoretical Chemistry, Sydney University, NSW 2006, Australia

Received March 19, 1990; Revised Manuscript Received August 10, 1990

\begin{abstract}
Kinetic information on particle growth is obtained for the ab initio emulsion polymerization of butadiene. It is shown that the decrease in particle number by coagulation (induced by the high ionic strength) hardly affects polymerization rate, since the average number of radicals per particle $(\bar{n})$ increases with particle size. From a rate analysis of intervals II and III it follows that the system is "zero-one" ( $\bar{n} \leq$ $0.5)$, i.e., termination is not rate-determining. Zero-one kinetics, in combination with a low initiator efficiency, explains the small effect of initiator concentration on polymerization rate. The radical loss mechanism responsible for the zero-one kinetics could not be established unambiguously, but chain transfer/desorption processes involving polybutadiene, thiol, surfactant, and the Diels-Alder dimer 4-vinyl-1-cyclohexene were all refuted on experimental grounds. Desorption of monomeric species seems a reasonable explanation, given the rather low estimate for the propagation rate coefficient.
\end{abstract}

\section{Introduction}

Despite the enormous industrial importance of polybutadiene-containing polymers prepared by emulsion polymerization (e.g., synthetic rubbers, high-impact materials, coatings, adhesives), very little is known about the kinetic behavior of butadiene in emulsion polymerization systems. As early as the American synthetic rubber program in World War II, unusual effects were observed in the (co)polymerization of butadiene (75\%)-styrene $(25 \%)$ or butadiene alone, but no adequate explanations were provided. These effects included the observations that trace amounts of thiols of low water solubility seemed to be essential to bring about reaction in persulfateinitiated polymerizations, ${ }^{1}$ while the rate of (co)polymerization was unaffected when changing the concentration of persulfate within wide limits. ${ }^{2}$

In previous publications ${ }^{3-5}$ we have reported on the $a b$ initio emulsion polymerization of butadiene under conditions typically found in industrial practice, e.g., high ionic strength, large monomer/water ratios, using a commercial surfactant. Although these experiments were not especially designed to study the kinetics, they do contain a lot of useful information, which is now used to analyze the typical behavior of this monomer.

One of the principal problems encountered in interpreting the polymerization kinetics of butadiene is the chronic lack of reliable rate coefficients in open literature. The only values for the propagation rate coefficient stem from the early work by Morton et $a .^{6}$ and at best represent an approximation of its true value since they were determined with ab initio polymerizations at low temperatures $\left(0-30^{\circ} \mathrm{C}\right)$, involving polydisperse latexes sized by the method of soap titration.

Within the limitations mentioned above, an analysis is given of the kinetics and mechanisms of the emulsion polymerization of butadiene.

\section{Experimental Section}

All materials used were of high purity, except the tert-dodecanethiol, which was a crude mixture of $\mathrm{C}_{12}$ isomers, and dresinate 214 , which was a disproportionated aqueous dispersion of abietic acid-type derivatives with dehydro-, dihydro-, and tetrahydroabietic acid as main components and less than $0.2 \%$ abi- etic acid. The standard recipes and reaction conditions are given in Table I, while experimental details are described elsewhere., ${ }^{4,5}$

Conversion data were based on the total solid content of samples collected with a high-pressure-proof syringe. The average particle diameter was measured by dynamic light scattering (DLS, Malvern IIc) and transmission electron microscopy (TEM, Philips 420 and Jeol $2000 \mathrm{FX}$ ). For TEM the latexes were hardened with $\mathrm{OsO}_{4}$ and typically some $750-1000$ particles were counted with a Zeiss TGA-10 particle analyzer. From DLS only the weightaverage diameter $d_{w}$ was used, while TEM gives complete information on average particle size and size distribution. The relevant definitions are given in Table II. The numerical values of $d_{w}$ measured with TEM and DLS usually coincide within 5\% as the particle size distributions are relatively narrow (average polydispersity index $P=1.08 \pm 0.03$ ).

The particle number density per unit volume of water $(N)$ was calculated according to

$$
N=\frac{6 c(m / w)}{\left(\rho_{\mathrm{p}} / \rho_{\mathrm{aq}}\right) \pi d^{3}}
$$

where $c$ is the fractional conversion, $m / w$ the monomer to water weight ratio, $\rho_{\mathrm{aq}}$ the density of aqueous phase, $\rho_{\mathrm{p}}$ the polymer density, and $d$ the average particle diameter.

\section{Results and Discussion}

It is convenient to divide the course of an emulsion polymerization into three distinct intervals. Interval $I$ is the initial stage where particle formation takes place. Interval II is characterized by a constancy of particle number, while polymerization in the particles proceeds in the presence of a separate monomer phase. The beginning of interval II is sometimes taken as the conversion where the surfactant concentration drops below its critical micelle concentration $(\mathrm{cmc})$. Interval III begins with the disappearance of monomer droplets, after which the monomer concentration in the particles starts to decrease continuously.

Coagulation Phenomena. Performing a polymerization with dresinate 214 (recipe 1) as surfactant gave a characteristic behavior, as depicted in Figure 1. Obviously, limited coagulation is involved in the particle formation process, and following the definition for interval II (viz., constancy of particle number in the presence of monomer droplets), this stage commences at ca. $40 \%$ conversion. Nevertheless, the polymerization rate $\left(R_{\mathrm{p}}\right)$ has already 
Table I

Standard Polymerization Recipes in Parts by Weight

\begin{tabular}{|c|c|c|}
\hline ingredient & recipe 1 & recipe 2 \\
\hline $\begin{array}{l}\text { water } \\
\text { butadiene } \\
\text { dresinate } 214 \\
\text { sodium dodecylsulfate } \\
\mathrm{K}^{+} / \mathrm{Na}^{+} \text {carbonate } \\
\mathrm{K}^{+} / \mathrm{Na}^{+} \text {persulfate } \\
\text { t-dodecanethiol }\end{array}$ & $\begin{array}{r}230 \\
100 \\
7.6 \\
\\
4.4 \\
0.8 \\
0.7\end{array}$ & $\begin{array}{r}230 \\
100 \\
7.6 \\
2.0 \\
0.7 \\
0.7\end{array}$ \\
\hline $\begin{array}{l}\text { [initiator] } \\
\text { temperature, }{ }^{\circ} \mathrm{C} \\
\mathrm{pH}\end{array}$ & \multicolumn{2}{|c|}{$\begin{array}{c}13 \mathrm{mmol} \cdot \mathrm{L}^{-1} \\
62 \\
10.5-10.8\end{array}$} \\
\hline
\end{tabular}

a In recipe 1 potassium salts were used, and in recipe 2 sodium salts were used.

Table II

Definitions of Relevant Particle Size Parameters, Where $n_{1}$ Represents the Number of Particles with Diameter $d_{1}^{*}$

\begin{tabular}{cccc}
\hline$d_{\mathfrak{n}}$ & $d_{\mathrm{v}}{ }^{3}$ & $d_{\mathrm{w}}$ & $P$ \\
\hline$\sum n_{\mathrm{i}} d_{\mathrm{i}} / \sum n_{\mathrm{i}}$ & $\sum n_{\mathrm{i}} d_{\mathrm{i}}{ }^{3} / \sum n_{\mathrm{i}}$ & $\sum n_{\mathrm{i}} d_{\mathrm{i}}{ }^{4} / \sum n_{\mathrm{i}} d_{\mathrm{i}}^{3}$ & $d_{\mathrm{w}} / d_{\mathrm{n}}$
\end{tabular}

a Subscripts: $n$ denotes number average, $v$ volume average, and $w$ weight average diameters.

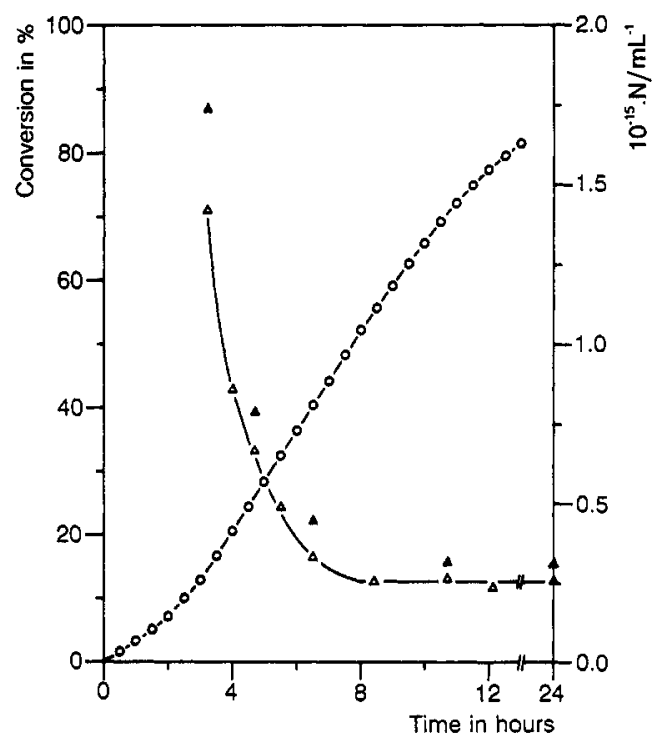

Figure 1. Conversion ( 0 ) and particle number $N$ vs time curves for a polymerization with $16.2 \mathrm{~g} \cdot \mathrm{L}^{-1}$ dresinate 214 (recipe 1 ). Particle number based on $d_{\mathrm{w}}$ obtained with light scattering $(\Delta)$ and $d_{v}$ obtained with electron microscopy $(\Delta)$.

become constant at about $25 \%$, when particle number $(N)$ is still decreasing. Obviously, $R_{\mathrm{p}}$ is not proportional to $N$, as is frequently assumed in emulsion polymerization. The same phenomenon was also observed when using sodium dodecylsulfate (recipe 2) as surfactant (Figure 2).

A similar behavior has been reported with more watersoluble monomers, such as methyl methacrylate, ${ }^{7}$ ethyl acrylate, ${ }^{8}$ and vinyl acetate. ${ }^{9}$ These systems are kinetically dominated by radical desorption, and the average number of radicals per particle $(\bar{n})$ can be much smaller than 0.5 , suggesting the feasibility of an analogous situation in the present system.

Limited coagulation has also been observed in surfactant-free polymerizations, ${ }^{10,11}$ while the role of coagulation in the particle nucleation mechanism has been treated quantitatively by several workers. ${ }^{12-14}$ However, coagulation in the present system seems qualitatively different. Butadiene is only sparingly water-soluble $\left(C_{\mathrm{aq}}=37\right.$ $\mathrm{mmol} \cdot \mathrm{L}^{-1}$ at $\left.50^{\circ} \mathrm{C}\right),{ }^{16}$ the surfactant concentrations are far above the cmc, ${ }^{4,5}$ and coagulation extends well beyond

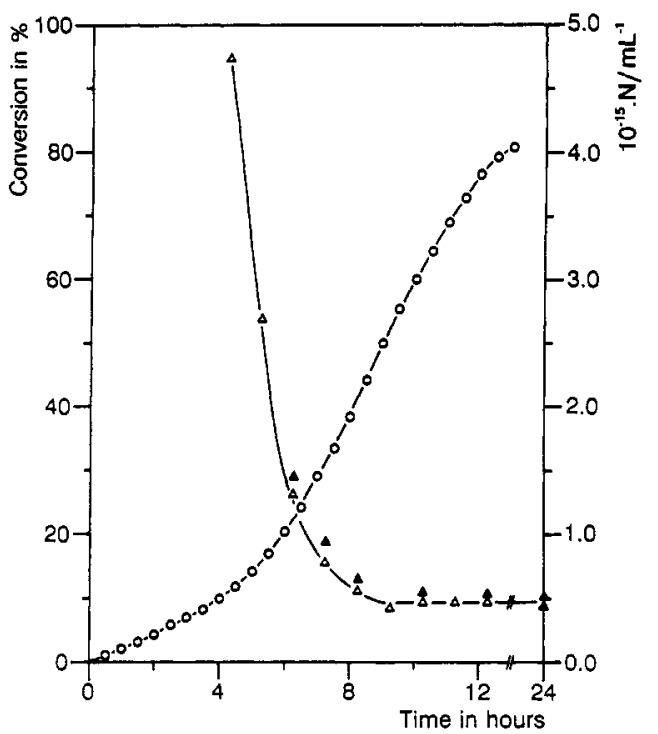

Figure 2. Conversion and particle number $N$ vs time curves for a polymerization with $8.1 \mathrm{~g} \cdot \mathrm{L}^{-1}$ sodium dodecylsulfate (recipe 2 ). For symbols see the caption to Figure 1.

the nucleation stage and involves particles of "normal" size. As shown previously, ${ }^{5}$ coagulation in this system is caused by the high ionic strength of the aqueous phase, in agreement with the general principles of electrostatic stabilization of colloidal particles outlined in DLVO theory. ${ }^{16}$ Although depending on the specific choice of reaction conditions, constancy of particle number after the disappearance of surfactant micelles seems more coincidental than characteristic.

Interval II Analysis. The overall rate of polymerization $R_{\mathrm{p}}$ is usually expressed as

$$
R_{\mathrm{p}}=\frac{\mathrm{d} c}{\mathrm{~d} t} n_{\mathrm{M}}{ }^{\circ}=k_{\mathrm{p}} C_{\mathrm{M}}\left(\bar{n} / N_{\mathrm{Av}}\right) N
$$

where $c$ is the fractional conversion, $n_{\mathrm{M}}{ }^{\circ}$ the number of moles of monomer initially present per unit volume of water, $k_{\mathrm{p}}$ the propagation rate coefficient, $C_{\mathrm{M}}$ the monomer concentration within the particles, and $N_{\mathrm{Av}}$ Avogadro's number. Since $k_{\mathrm{p}}$ is not known with sufficient accuracy, it is better to use the average rate per particle $\left(R_{\mathrm{p}} / N\right)$ as a semiquantitative equivalent of $\bar{n}$, because $k_{\mathrm{p}}$ and $C_{M}$ are both constant in interval II to within an excellent approximation (see below).

Calculating $R_{\mathrm{p}} / N$ using $R_{\mathrm{p}}$ in interval II and the final particle number after cessation of coagulation gives an upper limit of this quantity, since at lower conversions $R_{\mathrm{p}} / N$ is evidently smaller due to the smaller particle size (Figure 3). Besides type and concentration of surfactant, other recipe parameters such as monomer/water ratio, ionic strength, and initiator concentration were utilized to vary the final particle size. Plotting the average rate per particle on a log-log scale as a function of final particle diameter at an arbitrarily chosen conversion, viz., $90 \%$ (Figure 4; $90 \%$ was chosen for the sake of experimental convenience, as the majority of polymerizations was stopped between 85 and $95 \%$ ) clearly shows that $R_{\mathrm{p}} / N$ (and thus $\bar{n}$ ) depends solely on particle size. Polymerization kinetics is internally consistent and otherwise uninfluenced by variables such as surfactant concentration and ionic strength, except in regard to how these affect final particle size.

Figure 4 also contains data points taken from the work of Wendler et al. ${ }^{17}$ for butadiene emulsion polymerizations at $70^{\circ} \mathrm{C}$, where particle size was varied by changing the amount of diisopropylxanthogen disulfide, a chain-transfer 


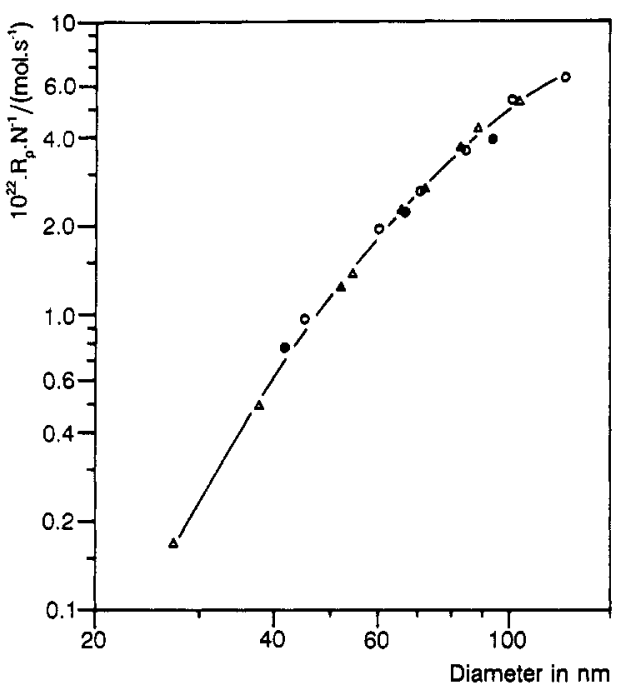

Figure 3. Average rate per particle $R_{\mathrm{p}} / N$ vs particle diameter, $d_{\mathrm{w}}$ (open symbols) and $d_{\mathrm{v}}$ (full symbols), for the polymerizations of Figure 1 (circles) and Figure 2 (triangles).

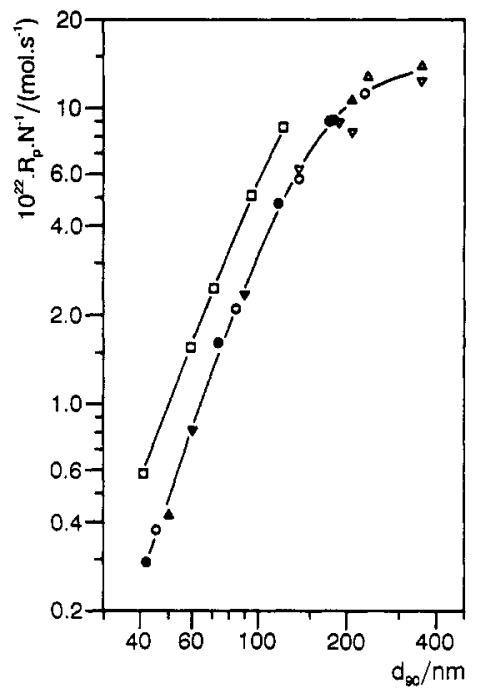

Figure 4. Average rate per particle $R_{\mathrm{p}} / N$ vs particle diameter $d_{\mathrm{v}}$ at $90 \%$ conversion $\left(d_{90}\right)$, for polymerizations with dresinate 214 (open symbols) and sodium dodecylsulfate (full symbols). The final particle size was varied by changing the surfactant concentration $(0)$, monomer/water ratio $(\nabla)$, or cation concentration $(\Delta)$ in the standard recipes. Data of Wendler et al. ${ }^{17}(\square)$ for polymerizations at $70^{\circ} \mathrm{C}$.

agent that decreases colloidal stability by introducing polar end groups that reduce surfactant adsorption. ${ }^{18}$ Agreement with our results is good, given the temperature difference of $8^{\circ} \mathrm{C}$.

Figures 3 and 4 are analogous to the well-known Ugelstad plots of $\log \bar{n}$ vs $\log \alpha^{\prime},{ }^{19}$ where $\alpha^{\prime}=\rho_{\mathrm{j}} v / N k_{\mathrm{t}}, \rho_{\mathrm{i}}$ the rate of radical production in the aqueous phase, $v$ the volume of a monomer-swollen particle, and $k_{t}$ the rate coefficient for bimolecular termination within the particles. Obviously $R_{\mathrm{p}} / N$ is proportional to $\bar{n}$. Since $N=V / v$, with $V$ the total volume of polymer per unit volume of the aqueous phase, it is easily seen that $\alpha^{\prime} \propto v^{2} \propto d^{6}$. At constant [I] (implying a constant $\rho_{\mathrm{i}}$ ), $\log \alpha^{\prime}$ can thus be replaced by $\log$ $d_{90}$ or $\log d$.

Using the uncertain value for $k_{\mathrm{p}}=100 \mathrm{~L} \cdot \mathrm{mol}^{-1} \cdot \mathrm{s}^{-1}$ reported by Morton et al. ${ }^{6}$ at $62^{\circ} \mathrm{C}$, and $C_{\mathrm{M}}=5.6 \mathrm{~mol} \cdot \mathrm{L}^{-1}$ (see the Appendix), a value of $4.7 \times 10^{-22} \mathrm{~mol} \cdot \mathrm{s}^{-1}$ for $R_{\mathrm{p}} / N$ would result if $\bar{n}=0.5$. Given this rough estimate of a Smith-Ewart case 2 situation (see below) and again emphasizing that the calculated values for $R_{\mathrm{p}} / N$ are upper

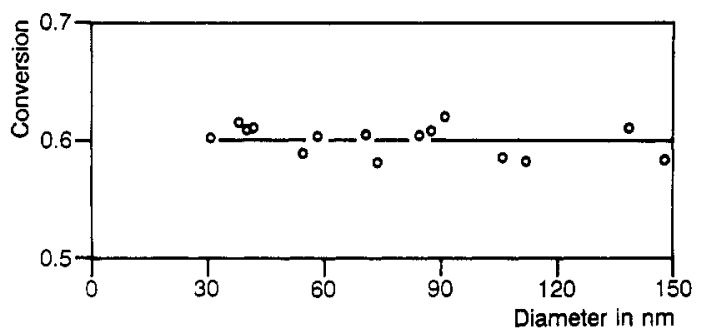

Figure 5. Fractional conversion where interval III begins $\left(x^{\prime}\right)$ vs particle diameter $d_{w}$ at $x^{\prime}$. Average value for $x^{\prime}=0.60$.

limits for the experiments involved, it is evident from Figures 3 and 4 that values for $\bar{n}<0.5$ are realistic.

Importantly, no constancy of $R_{\mathrm{p}} / N$ associated with $\bar{n}=$ 0.5 is observed in the particle size range covered. The apparent leveling off at $d_{90}>200 \mathrm{~nm}$ may be artificial, because the polymerizations involved are extremely slow, sometimes taking 2-3 days to complete conversion. On such a time scale bulk polymerization in the monomer droplets can no longer be neglected as is usually done. This behavior clearly shows up in the particle size distributions of the final latexes, which are extremely positively skewed. Therefore, these experiments are ignored in the following discussion.

Interval III Analysis. The complications associated with particle nucleation and coagulation can be avoided by using the kinetic information in interval III, where particle number is truly constant, as shown in Figures 1 and 2. Since monomer concentration in the particles is decreasing continuously, it is convenient to remove $C_{M}$ from the right side of eq 2 and write the expression in terms of the fractional conversion in interval III, $x$, with $x=\left(C_{\mathrm{M}}{ }^{\circ}-C_{\mathrm{M}}\right) / C_{\mathrm{M}}{ }^{\circ}$ and $C_{\mathrm{M}}{ }^{\circ}$ the initial monomer concentration in the particles ${ }^{20}$

$$
-\frac{\mathrm{d} \ln (1-x)}{\mathrm{d} t}=\frac{k_{\mathrm{p}} \bar{n} C_{\mathrm{M}}{ }^{\circ} N}{N_{\mathrm{Av}} n_{\mathrm{M}}}
$$

where $n_{\mathrm{M}}$ is the number of moles of monomer per unit volume of water present at the beginning of interval III.

Since $n_{\mathrm{M}}=\left(1-x^{\prime}\right) n_{\mathrm{M}}{ }^{\circ}$, with $x^{\prime}$ the conversion where interval III begins, we can calculate $x^{\prime}$ from the experimental values of interval II $\left(R_{\mathrm{p}}\right)$ and interval III rate $(-\mathrm{d} \ln (1-x) / \mathrm{d} t)$. The conversion $x^{\prime}$ is found to be 0.60 (standard deviation $=2.3 \%$, using 25 data points) and independent of particle size (Figure 5). This latter observation further substantiates the common assumption of constancy of $C_{M}$ in interval II. The value of $x^{\prime}$ is somewhat higher than those reported in the literature based on vapor pressure measurements, viz., $0.52^{21}$ and $0.56{ }^{6}$ These latter values are considered more inaccurate because the nonideal gas behavior of butadiene vapor complicates an accurate determination of the conversion at the point where pressure begins to drop.

For the simple zero-one system (i.e., only particles with zero or one free radical need to be considered) where bimolecular termination is not rate-determining, it is easily shown that ${ }^{22}$

$$
\bar{n}=\frac{\rho}{2 \rho+k}
$$

where $\rho$ is the pseudo-first-order rate coefficient for entry of radicals into particles and $k$ the rate coefficient for radical exit ("desorption"). During interval III $\rho$ may be considered unchanging to within a good approximation, since the swollen particle diameter is almost constant. On the other hand, $k$ may depend on factors other than the particle volume (e.g., $C_{\mathrm{M}}$ ). A reasonable starting point is 


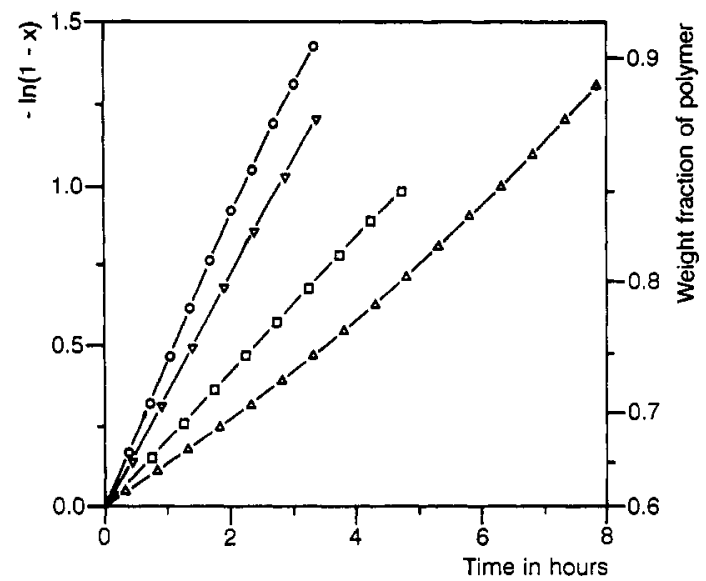

Figure 6. $-\ln (1-x)$ vs reaction time in interval III, for polymerizations at different dresinate 214 concentrations: 64.8 $\mathrm{g} \cdot \mathrm{L}^{-1}(0) ; 32.4 \mathrm{~g} \cdot \mathrm{L}^{-1}(\nabla) ; 16.2 \mathrm{~g} \cdot \mathrm{L}^{-1}(\square) ; 8.1 \mathrm{~g} \cdot \mathrm{L}^{-1}(\Delta)$. On the right axis is indicated the weight fraction of polymer $w_{\mathbf{p}}$.

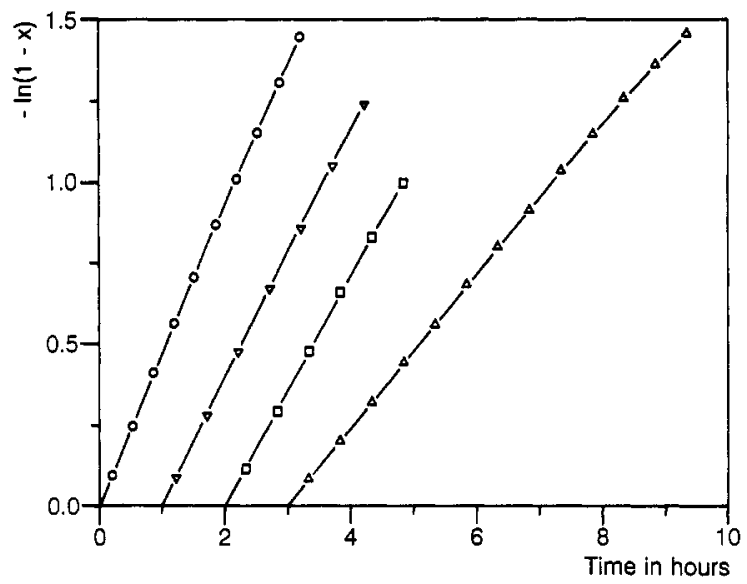

Figure 7. $-\ln (1-x)$ vs reaction time in interval III, for polymerizations at different sodium dodecylsulfate concentrations: $64.8 \mathrm{~g} \cdot \mathrm{L}^{-1}(0) ; 32.4 \mathrm{~g} \cdot \mathrm{L}^{-1}(\nabla) ; 16.2 \mathrm{~g} \cdot \mathrm{L}^{-1}(\square) ; 8.1 \mathrm{~g} \cdot \mathrm{L}^{-1}(\Delta)$. For convenience the zero-point is shifted $1 \mathrm{~h}$ along the $x$-axis for each experiment.

to assume $k$ to be constant and then to check if this is consistent with the data. Several limiting cases can be distinguished:

$$
\begin{array}{ll}
\text { Smith-Ewart case 2, with } k \ll \rho: & \bar{n}=0.5 \\
\text { Smith-Ewart case 1, with } k \gg \rho: & \bar{n} \simeq \rho / k
\end{array}
$$

Plotting $-\ln (1-x)$ vs reaction time (Figures 6 and 7$)$ gives straight lines up to a weight fraction of polymer in the particles $w_{\mathrm{p}}$ (equivalent to the ab initio fractional conversion $c$ ) of 0.85 or higher, for all polymerizations with $d_{90}<175 \mathrm{~nm}$.

Although the bimolecular termination rate coefficient varies significantly with $w_{\mathrm{p}}$, termination cannot be ratedetermining in these experiments because $-\mathrm{d} \ln (1-x) / \mathrm{d} t$ is constant for $0.60<w_{\mathrm{p}}<0.85$ under all conditions investigated. The approximation of instantaneous termination is thus valid, and $\bar{n} \leq 0.5$.

Furthermore, Figures 6 and 7 show that the product of $k_{\mathrm{p}} \tilde{n}$ is constant within each experiment; it would be highly fortuitous if $k_{\mathrm{p}}$ and $\bar{n}$ would counterbalance under all experimental conditions tried, so it is apparent that $k_{\mathrm{p}}$ and $\bar{n}$ are both constant in interval III. This further implies that $k_{\mathrm{p}}$ is not diffusion controlled, at least for $w_{\mathrm{p}}<0.85$; this is to be expected given the low glass transition temperature of polybutadiene prepared by emulsion polymerization $\left(T_{\mathrm{g}}=-86^{\circ} \mathrm{C}\right) . .^{23}$
Table III

Initiator Exponents for the Particle Number $\left(N \propto[I]^{\pi}\right)$ and Polymerization Rates in Interval II $\left(\boldsymbol{R}_{\mathrm{p}} \propto[\mathrm{I}]^{y}\right)$ and Interval III $\left(-\mathrm{d} \ln (1-x) / \mathrm{d} t \propto[I]^{8}\right)$, at Different Surfactant Concentrations [S] and Overall Cation Concentrations [cation]

\begin{tabular}{cccccccc}
\hline recipe & $\begin{array}{c}\text { [S], } \\
\mathbf{g} \cdot \mathrm{L}^{-1}\end{array}$ & $\begin{array}{c}\text { [cation], } \\
\text { mol. } \cdot \mathrm{L}^{-1}\end{array}$ & $n^{a}$ & $x$ & $y$ & $z$ & $\begin{array}{c}d_{90}{ }^{b} \\
\text { nm }\end{array}$ \\
\hline 2 & 32.4 & 0.3 & 9 & 0.46 & 0.04 & 0.04 & 46 \\
2 & 16.2 & 0.3 & 7 & 0.16 & 0.09 & 0.09 & 80 \\
1 & 32.4 & 0.4 & 7 & 0.02 & 0.08 & & 94 \\
\multicolumn{7}{c}{$n=$ number of experiments. ${ }^{b} d_{\mathbf{w}}$ at $[\mathrm{I}]=13.0 \mathrm{mmol} \cdot \mathrm{L}^{-1}$. }
\end{tabular}

The pseudo-first-order termination rate coefficient may start to become sufficiently small for very large particles as to become rate-determining, consistent with the nonlinearity of $-\ln (1-x)$ observed for polymerizations with $d_{90}>175 \mathrm{~nm}$ (e.g., the polymerization with $8.1 \mathrm{~g} \cdot \mathrm{L}^{-1}$ dresinate 214 in Figure 6, with $d_{\mathrm{v}}=180 \mathrm{~nm}$ at $90 \%$ conversion). At a relatively low $w_{\mathrm{p}}$ of ca. 0.7 , the interval III rate $-\mathrm{d}$ ln $(1-x) / \mathrm{d} t$, and thus $\bar{n}$, begins to increase. Termination is no longer instantaneous, yet the initial steady state suggests a zero-one behavior at lower $w_{\mathrm{p}}$. If we assume the initial $\bar{n}=0.5$, an estimation for $k_{\mathrm{p}}=180-200$ $\mathrm{L} \cdot \mathrm{mol}^{-1} \cdot \mathrm{s}^{-1}$ is obtained. Although intuitively not unreasonable, this assumption is not necessarily correct, since the initial $\bar{n}$ can still be $<0.5$. The particle size distributions of these latexes are narrow, yet not monodisperse, which further complicates a proper interpretation. Therefore, this estimate of $k_{\mathrm{p}}$ should be regarded as a lower limit of its true value.

Effect of the Initiator Concentration. Having established that the studied system shows zero-one behavior over a wide range of experimental conditions, we can further explain the effect of initiator concentration [I] on polymerization kinetics (Table III). The initiator concentration was varied 100 -fold between 0.26 and 26.0 $\mathrm{mmol} \cdot \mathrm{L}^{-1}$, while every change of [I] was accompanied by an appropriate adjustment of the amount of sodium or potassium carbonate to keep the overall cation concentration [cation] constant. Under all conditions tried and in agreement with previously reported results, ${ }^{2}$ both $R_{\mathrm{p}}$ and $-\mathrm{d} \ln (1-x) / \mathrm{d} t$ are only weakly dependent on [I].

As limited coagulation is promoted (by lowering the surfactant concentration [S] or raising [cation]), the effect of [I] on $N$ diminishes, since the final particle number becomes predominantly determined by coagulation. This effect appears to be relatively small in the first series of experiments from Table III, since the initiator exponent for $N$, viz., 0.46 , is close to the theoretical value of 0.40 predicted by simple micellar ${ }^{24}$ and homogeneous nucleation theories ${ }^{25}$ that ignore coagulation.

The average rates per particle as a function of particle size for the first two series of experiments (recipe 2) from Table III are shown in Figure 8, where the solid line represents the best fit of data points from Figure 4. Again the kinetics is internally consistent, yet the 100 -fold variation of [I] has an almost neglible effect. This implies that $\alpha^{\prime}$ (and thus $\rho$ ) is independent of [I] in the present system; i.e., initiator efficiency must be extremely low. Furthermore, for latexes with a narrow particle size distribution, $\rho$ can be taken to be inversely proportional to $N$, as is proven in a new model for radical entry proposed by Maxwell et al., ${ }^{26}$ a model that has been found to give agreement with all extant data for $\rho$, including variation with $N$.

Substituting this into eqs 2 and 3 and assuming a low value for $\bar{n}$, viz., $\bar{n} \simeq \rho / k$, render both $R_{\mathrm{p}}$ and $-\mathrm{d} \ln (1-$ $x) / \mathrm{d} t$ independent of $[I]$ and $N$. This is in good agreement 


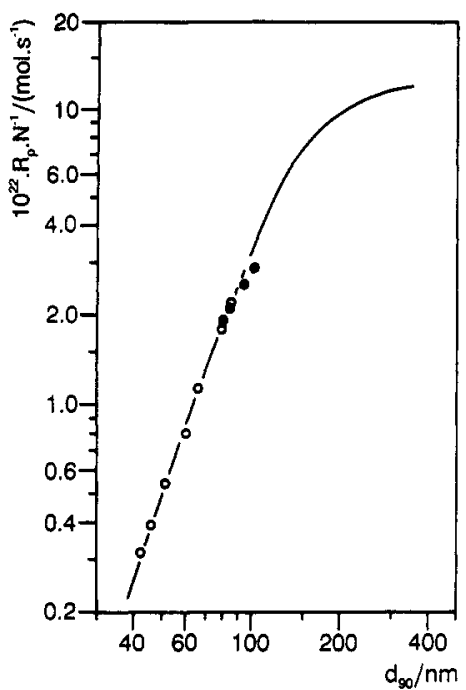

Figure 8. Average rate per particle $R_{\mathrm{p}} / N$ vs particle diameter $d_{w}$ at $90 \%$ conversion $\left(d_{90}\right)$, for polymerizations with a 100 -fold variation in persulfate concentration (see Table III) at two sodium dodecylsulfate concentrations (recipe 2): $32.4 \mathrm{~g} \cdot \mathrm{L}^{-1}(\mathrm{O})$ and 16.2 $g \cdot \mathrm{L}^{-1}(\bullet)$. The solid line represents the empirical relationship from Figure 4.

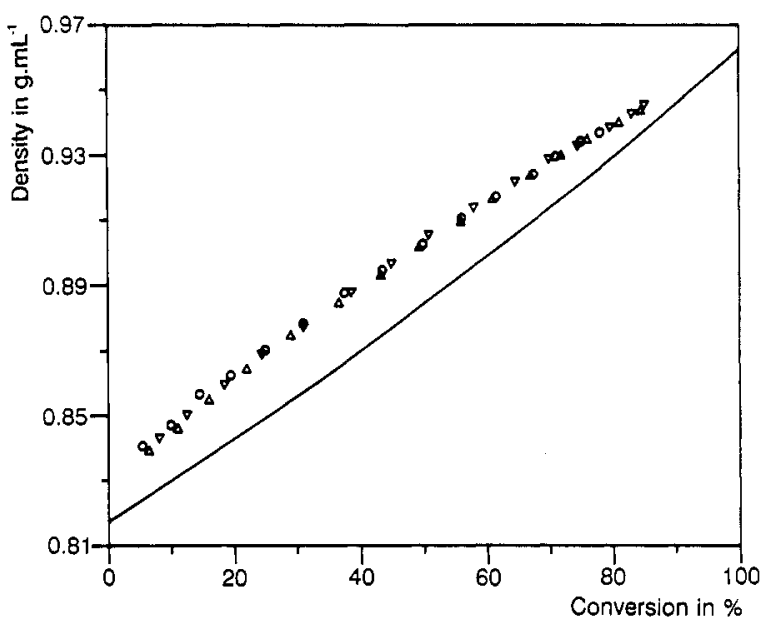

Figure 9. Density of the reaction mixture vs gravimetric conversion. Symbols represent experimental points from three polymerizations using recipe 1 , and the solid line, the theoretical relationship, assuming ideal mixing of monomer and polymer.

with the data summarized in Table III, especially for the first series of experiments, since the above assumption of $\bar{n} \ll 0.5$ is most valid for small particles. The reason for the very weak dependence of $\rho$ on [I] is as yet uncertain and is the subject of current theoretical and experimental investigation.

Radical Loss Mechanisms. It is obvious that a firstorder radical loss process is kinetically dominant in this system, whose nature is as yet uncertain. Several possibilities may arise:

1. First-order termination by monomer occlusion is highly unlikely, since monomer and polymer are completely miscible (or highly swellable if the polymer is crosslinked), while the glass transition temperature $\left(T_{\mathrm{g}}=-86\right.$ $\left.{ }^{\circ} \mathrm{C}\right)^{23}$ is well below the reaction temperature of $62^{\circ} \mathrm{C}$.

2. Radical trapping by transfer to polybutadiene, as proposed by Hagiopol et al. ${ }^{27}$ for the emulsion copolymerization of styrene and acrylonitrile in the presence of polybutadiene, is not important, since $-\mathrm{d} \ln (1-x) / \mathrm{d} t$ (and thus $\tilde{n}$ ) is constant over a period of several hours, whereas $w_{\mathrm{p}}$ changes significantly during this time.

3. Chain transfer to thiol and subsequent desorption of thiol radicals can also be ruled out, since Nomura et
Table IV

Number-Average $\left(M_{n}\right)$ and Weight-Average $\left(M_{\nabla}\right)$ Molecular Weights Determined by GPC of Polystyrene Samples, Prepared According to Recipe $2^{b}$ at $50{ }^{\circ} \mathrm{C}$, without tert-Dodecanethiol (TDT) and Different Amounts of 4-Vinyl-1-cyclohexene (VCH)

\begin{tabular}{ccccccc}
\hline $\mathrm{VCH}^{a}$ & $0 \%$ & $0.25 \%$ & $1 \%$ & $2 \%$ & $4 \%$ & $0 \%^{c}$ \\
\hline $10^{-5} M_{\mathrm{n}}$ & 4.1 & 4.3 & 3.9 & 3.8 & 3.9 & 0.49 \\
$10^{-6} M_{\mathrm{w}}$ & 2.1 & 2.5 & 2.3 & 1.8 & 1.7 & 0.21
\end{tabular}

- Weight percentage of $\mathrm{VCH}$ (and TDT) on monomer basis. ${ }^{b}[\mathrm{I}]=13.0 \mathrm{mmol} \cdot \mathrm{L}^{-1}$ and $[\mathrm{S}]=16.2 \mathrm{~g} \cdot \mathrm{L}^{-1} \cdot{ }^{c} 1 \%$ TDT added.

al. ${ }^{28}$ showed that $n$-dodecanethiol radicals do not desorb because of their extremely low water solubility. Furthermore, omitting the thiol from the recipes used in this investigation never increased $R_{\mathrm{p}} / N$, as would be expected in the case of desorption of thiol radicals. Instead, a marked decrease of $R_{\mathrm{p}} / N$ was sometimes observed. ${ }^{3}$

4. It is well-known that butadiene easily undergoes Diels-Alder cyclizations at elevated temperatures, giving products such as 4-vinyl-1-cyclohexene (VCH). Although it is described as a mild retarder in the copolymerization of butadiene ( $75 \%$ ) -styrene ( $25 \%$ ), ${ }^{29}$ addition of $1 \% \mathrm{VCH}$ to a butadiene emulsion polymerization using sodium dodecylsulfate (recipe 2) had no effect whatsoever either on the conversion-time history or on the final particle number. Furthermore, addition up to $4 \% \mathrm{VCH}$ to a styrene emulsion polymerization (using recipe 2 without thiol at $50{ }^{\circ} \mathrm{C}$ ) did not affect the molecular weight significantly (Table IV). Although inherently present during polymerization, this Diels-Alder dimer does not seem to facilitate the extensive radical desorption observed experimentally.

5. Many common surfactants (including sodium dodecylsulfate) can act as chain-transfer agents. ${ }^{30}$ However, this phenomenon cannot be of major importance in the present system, since polymerizations yielding the same final particle size have the same value for $R_{\mathrm{p}} / N$, regardless of the type of surfactant.

6. Last, transfer to monomer (or dead oligomeric material) followed by exit of the monomeric radical seems reasonable, given the rather low estimate of $k_{\mathrm{p}}$ and the moderate water solubility of butadiene.

In the transfer/diffusion model developed by Nomura and Harada, ${ }^{31,32}$ a propagating polymer chain transfers its free-radical activity to a monomer molecule (or to a chaintransfer agent), which then diffuses to the particle surface where it desorbs. The process is completed when the radical diffuses away from the surface into the bulk aqueous phase. When all of these three sequential events are significant, the exit rate coefficient $k$ is given by

$$
k=\frac{12 z D_{\mathrm{aq}}}{\left(q+2 D_{\mathrm{aq}} / D_{\mathrm{p}}\right) d_{\mathrm{sw}}^{2}} \frac{k_{\mathrm{tr}}}{k_{\mathrm{p}}}
$$

where $D_{\mathrm{aq}}$ and $D_{\mathrm{p}}$ are the diffusion coefficients of the exiting species in the aqueous phase and in the particle, respectively, $z$ is roughly equal to the maximum degree of polymerization of the exiting radical (The parameter $z=$ $\sum\left[k_{\mathrm{p}} C_{\mathrm{M}} /\left(k \tilde{n}+k_{\mathrm{p}} C_{\mathrm{M}}\right)\right]^{j}$, where $k$ is a desorption rate coefficient and $j$ the degree of polymerization of the exiting species, with $1 \leq j \leq j_{\max }$. When $k_{\mathrm{p}} C_{\mathrm{M}} \gg k n$, this gives $z \simeq j_{\max }$.), $d_{\mathrm{sw}}$ is the swollen particle diameter, and $k_{\mathrm{tr}}$ and $k_{\mathrm{p}}$ are the rate coefficients for transfer to monomer and for propagation, respectively. The parameter $q$ is the partition coefficient of the exiting species between the particles and the aqueous phase and is roughly equal to the ratio of saturated monomer solubilities in the particles 
and the aqueous phase $C_{\mathrm{M}} / C_{\mathrm{aq}}$. A similar expression was derived by Hansen and Ugelstad. ${ }^{33}$

If in the transfer/diffusion mechanism for radical exit transfer to monomer is the rate-determining step, eq 5 can be replaced by ${ }^{34}$

$$
k \simeq k_{\mathrm{tr}} C_{\mathrm{M}}
$$

Obviously, this is not the case in the present system, since $\bar{n}$, and thus $k$, was found constant far into interval III, whereas $C_{\mathrm{M}}$ decreases continuously. However, the constancy of $k$ is consistent with the general eq 5 , since $d_{\mathrm{sw}}$ and $q$ are not expected to vary significantly in interval III.

For a sparingly water-soluble monomer, $q \gg 2 D_{\mathrm{aq}} / D_{\mathrm{p}}$, so that eq 5 can be approximated by ${ }^{34}$

$$
k \simeq \frac{12 z D_{\mathrm{aq}}}{d_{\mathrm{sw}}{ }^{2}} \frac{k_{\mathrm{tr}}}{k_{\mathrm{p}}} \frac{C_{\mathrm{aq}}}{C_{\mathrm{M}}}
$$

On the basis of eq 7 the exit rate coefficient $k$ for butadiene is expected to be at least 1 order of magnitude larger than the one for styrene, where $\bar{n}$ is often found close to 0.5 within fairly wide experimental limits:

(a) $k_{\mathrm{p}}$ for butadiene $\left(\mathrm{ca} .200 \mathrm{~L} \cdot \mathrm{mol}^{-1} \cdot \mathrm{s}^{-1}\right)$ is significantly smaller than the one for styrene $\left(380 \mathrm{~L} \cdot \mathrm{mol}^{-1} \cdot \mathrm{s}^{-1}\right.$ at 62 ${ }^{\circ} \mathrm{C}^{35}$ ).

(b) $C_{\mathrm{aq}}=37 \mathrm{mmol} \cdot \mathrm{L}^{-1}$ for butadiene, ${ }^{15}$ and $C_{\mathrm{aq}}=3.7$ $\mathrm{mmol} \cdot \mathrm{L}^{-1}$ for styrene, ${ }^{36}$ both at $50^{\circ} \mathrm{C}$.

(c) On the basis of chemical structure, the maximum degree of polymerization of the exiting species $z$ is expected to be roughly 2 times larger for butadiene $\left(\mathrm{C}_{4} \mathrm{H}_{6}\right)$ as compared with styrene $\left(\mathrm{C}_{8} \mathrm{H}_{8}\right)$.

Experimental evidence is as yet insufficient to further substantiate this possibility, although as mentioned previously the similarity with emulsion polymerizations of more water-soluble monomers, kinetically dominated by desorption of monomeric radicals, is suggestive of an analogous behavior for butadiene.

Further research (seeded experiments with monodisperse latexes are currently underway) is necessary to elucidate the exact kinetic scheme, but the results presented here give a better understanding of the behavior of this widely used monomer in emulsion polymerization systems.

The basic conclusions of this kinetic study are as follows:

1. In these typical butadiene emulsion homopolymerizations, termination is not rate-determining (except perhaps for very large particles), so that $\bar{n} \leq 0.5$.

2. Over the range of particle number and initiator concentrations studied, the entry rate coefficient is only very weakly dependent on initiator concentration.

3. Loss of free-radical activity within the particles is a first-order process, which may be transfer to monomer followed by exit.

Acknowledgment. We are indebted to DSM Research, Geleen, The Netherlands, for financially supporting this work. We thank Ian A. Maxwell for a stimulating discussion.

\section{Appendix. Calculation of the Saturation Monomer Concentration}

The beginning of interval III at conversion $x^{\prime}$ corresponds to a situation where the unreacted monomer is almost completely imbibed in the latex particles. Mutual solubility of butadiene and water is low enough to be ignored.

Taking conversion $x^{\prime}=0.60$ (see Results and Discussion) and using $\rho_{\mathrm{p}}=0.88 \mathrm{~g} \cdot \mathrm{mL}^{-1}$ and $\rho_{\mathrm{M}}=0.565 \mathrm{~g} \cdot \mathrm{mL}^{-1}$ at 62 ${ }^{\circ} \mathrm{C}$, a value for $C_{\mathrm{M}}=5.32 \mathrm{~mol} \cdot \mathrm{L}^{-1}$ is obtained, assuming ideal mixing of monomer and polymer. However, systems like these rarely behave ideally, which is revealed by measurements of the density of the polymerization system as a function of conversion. For this purpose an Anton Paar density meter with a remote cell (DMA 401; maximum pressure $10 \mathrm{~atm}$.) was employed. Samples were taken at regular time intervals, in between which the cell was flushed with distilled water. Conversions were determined gravimetrically as described previously (see the Experimental Section).

The experimentally determined density-conversion relationship (Figure 9) differs markedly from that calculated assuming ideal mixing of monomer and polymer and additivity of specific volumes of the separate phases. At conversions $<50 \%$ the discrepancy between ideality and experiment is partly caused by the instability of the monomer emulsion. Demixing started seconds after the cell was filled with a fresh latex sample. In the absence of a steady signal the minimum value for the density was taken, which can introduce a serious systematic error. It should be noted that this minimum value was quite reproducible. In contrast, at conversions $>50 \%$ measurements were free of this artifact and can be used without reservations.

At conversion $x^{\prime}=0.60$ only the aqueous phase and the monomer-swollen latex particles have to be considered. Additivity of the specific volumes of both phases is justified, since mutual solubility is negligible. From the experimentally determined density at $60 \%$ conversion, the density of the swollen particles can be calculated. A volume contraction factor can be defined as the ratio of "ideal" to experimental density of the swollen particles, which was found to be 0.95 . The saturation monomer concentration $C_{\mathrm{M}}$ corrected for nonideal mixing of monomer and polymer thus becomes $5.6 \mathrm{~mol} \cdot \mathrm{L}^{-1}$ and was found independent of (unswollen) particle diameters between 30 and $150 \mathrm{~nm}$ (Figure 5).

\section{References and Notes}

(1) Kolthoff, I. M.; Harris, W. E. J. Polym. Sci. 1947, 2, 41.

(2) Bovey, F. A.; Kolthoff, I. M.; Medalia, A. I.; Meehan, E. J. In Emulsion Polymerization; Interscience Publishers: New York, 1955.

(3) Weerts, P. A.; van der Loos, J. L. M.; German, A. L. Polym. Commun. 1988, 29, 278.

(4) Weerts, P. A.; van der Loos, J. L. M.; German, A. L. Makromol. Chem. 1989, 190, 777

(5) Weerts, P. A.; van der Loos, J. L. M.; German, A. L. Makromol. Chem. 1990, 191, 2615.

(6) Morton, M.; Salatiello, P. P.; Landfield, H. J. Polym. Sci. 1952 , $8,215$.

(7) Fitch, R. M.; Tsai, C. H. In Polymer Colloids; Fitch, R. M., Ed.; Plenum: New York, 1971.

(8) Yeliseyeva, V. I. In Emulsion Polymerization; Piirma, I., Ed.; Academic Press: New York, 1982.

(9) Dunn, A. S.; Chong, L. C. H. Br. Polym. J. 1970, 2, 49.

(10) Goodwin, J. W.; Hearn, J.; Ho, C. C.; Ottewill, R. H. Br. Polym. J. $1973,5,347$.

(11) Goodall, A. R.; Wilkinson, M. C.; Hearn, J. J. Polym. Sci., Polym. Chem. Ed. 1977, 15, 2193.

(12) Hansen, F. K.; Ugelstad, J. J. Polym. Sci., Polym. Chem. Ed. $1978,16,1953$

(13) Feeney, P. J.; Napper, D. H.; Gilbert, R. G. Macromolecules $1984,17,2520$

(14) Song, Z.; Poehlein, G. W. J. Macromol. Sci., Chem. 1988, A25, (12), 403 and 1587 .

(15) Reed, C. D.; McKetta, J. J. J. Chem. Eng. Data 1959, 4, 294.

(16) Ottewill, R. H. In Emulsion Polymerization; Piirma, I., Ed.; Academic Press: New York, 1982.

(17) Wendler, K.; Karim, N.; Fedtke, M. Plaste Kautsch. 1983, 30, 247.

(18) Wendler, K.; Elsner, H.; Hergeth, W. D.; Fedtke, M. Plaste Kautsch. 1985, 32, 128.

(19) Ugelstad, J.; Mörk, P. C.; Aasen, J. O. J. Polym. Sci., Polym. Chem. Ed. 1967, 5, 2281 . 
(20) James, D. R.; Sundberg, D. C. J. Polym. Sci., Polym. Chem. Ed. $1980,18,903$.

(21) Meehan, E. J. J. Am. Chem. Soc. 1949, 71, 628.

(22) Gilbert, R. G.; Napper, D. H. J. Macromol. Sci., Rev. Macromol. Chem. Phys. 1983, C23, 127.

(23) Wood, L. A. In Synthetic Rubber; Whitby, G. S., Davis, C. C., Dunbrook, R. F., Eds.; John Wiley \& Sons: New York, 1954; p 358.

(24) Smith, W. J.; Ewart, R. H. J. Chem. Phys. 1948, 16, 592.

(25) Roe, C. P. Ind. Eng. Chem. 1968, 60, 20.

(26) Maxwell, I. A.; Morrison, B. R.; Napper, D. H.; Gilbert, R. G. In Integration of Fundamental Polymer Science and Technology 4; Fourth Rolduc Polymer Meeting; Lemstra, P. J., Kleintjens, L. A. Eds.; Elsevier: New York, 1990; pp 116-125. Maxwell, I. A.; Morrison, B. R.; Napper, D. H.; Gilbert, R. G. Macromolecules, in press.

(27) Hagiopol, C.; Deleanu, T.; Memetea, T. J. Appl. Polym. Sci. $1989,37,947$.

(28) Nomura, M.; Minamino, Y.; Fujita, K.; Harada, M. J. Polym. Sci., Polym. Chem. Ed. 1982, 20, 1261.
(29) Taft, W. K.; Tiger, G. J. In Synthetic Rubber; Whitby, G. S.; Davis, C. C.; Dunbrook, R. F., Eds.; John Wiley \& Sons: New York, 1954; p 683.

(30) Piirma, I.; Kamath, V. R.; Morton, M. J. Polym. Sci., Polym. Chem. Ed. 1975, 13, 2087.

(31) Nomura, M.; Harada, M. J. Appl. Polym. Sci. 1981, 26, 17.

(32) Nomura, M. In Emulsion Polymerization; Piirma, I., Ed.; Academic Press: New York, 1982.

(33) Hansen, F. K.; Ugelstad, J. Makromol. Chem. 1979, 180, 2423.

(34) Adams, M.; Napper, D. H.; Gilbert, R. G.; Sangster, D. F. J. Chem. Soc,, Faraday Trans. 1 1979, 82, 1979.

(35) Lansdowne, S. W.; Gilbert, R. G.; Napper, D. H.; Sangster, D. F. J. Chem. Soc., Faraday Trans. 1 1980, 76, 1344.

(36) Bovey, F. A.; Kolthoff, I. M. J. Polym. Sci. 1950, 5, 487. Mentioned in ref 2.

Registry No. VCH, 100-40-3; butadiene, 106-99-0; dresinate 214, 39389-48-5; sodium dodecylsulfate, 151-21-3. 